\title{
A rare case of spontaneous heterotopic pregnancy with successful pregnancy outcome following laparoscopic management of coexisting ruptured tubal pregnancy in Non-ART set up
}

\author{
G. D. Maiti*, Tony Jose, Shilpa Gupta, Vibhu Chatterjee
}

Department of Obstetrics and Gynaecology, Command Hospital (EC), WBUHS, Kolkata, West Bengal, India

Received: 13 April 2018

Accepted: 05 May 2018

\author{
*Correspondence: \\ Dr. G. D. Maiti, \\ E-mail: gdmaiti@rediffmail.com
}

Copyright: (c) the author(s), publisher and licensee Medip Academy. This is an open-access article distributed under the terms of the Creative Commons Attribution Non-Commercial License, which permits unrestricted non-commercial use, distribution, and reproduction in any medium, provided the original work is properly cited.

\begin{abstract}
Heterotopic pregnancy is a rare clinical condition where both intrauterine (IU) and extra uterine pregnancy coexists. In a non-ART set up diagnosis of tubal ectopic pregnancy becomes challenging and difficult with coexisting intrauterine viable pregnancy, even when presents with ruptured form. Author is presenting one of his challenging experience in managing successfully such type of heterotopic ruptured tubal pregnancy in first trimester where extra uterine ruptured tubal pregnancy was addressed by laparoscopic salpingectomy under spinal anaesthesia with minimal uterine manipulation to continue intrauterine pregnancy till term and thus had a successful pregnancy outcome.
\end{abstract}

Keywords: Heterotopic pregnancy, Laparoscopic management

\section{INTRODUCTION}

Heterotopic pregnancy is simultaneous presence of intrauterine (IU) and extra uterine pregnancy with an incidence is $1 / 30,000$ of all spontaneous pregnancies (1). This condition may also be called as combined ectopic pregnancy, multiple sited or coincident pregnancy. In heterotopic pregnancy one of each fertilized ovum implants simultaneously in normal uterine cavity and other in extra uterine ectopic site respectively. There has been significant increase in incidence in women undergoing ovulation induction and assisted reproductive techniques such as In Vitro Fertilization (IVF), Gamete Intrafallopian Transfer (GIFT), etc.

Here authors are presenting a rare case of spontaneous heterotopic pregnancy where both diagnostic and management challenges are described. The ruptured tubal ectopic was successfully managed by laparoscopic salpingectomy without using uterine manipulator. The intrauterine pregnancy continued till term and had a successful pregnancy outcome.

\section{CASE REPORT}

Mrs. ZA, 25 years old, primigravidae, reported with amenorrhoea of 09 weeks, pain lower abdomen and minimal bleeding PV of $24 \mathrm{hrs}$ duration. Her vitals were stable with a pulse rate of $100 / \mathrm{min}$ and BP of $110 / 70 \mathrm{~mm}$ of $\mathrm{Hg}$. Mild abdominal distension with lower abdominal tenderness was evident on abdominal examination. Genital examination revealed minimal vaginal bleeding from a closed cervical os. The uterus was 8 weeks size with marked cervical motion tenderness. Her urine for pregnancy test was positive. She was provisionally diagnosed as threatened abortion. On investigation, her $\mathrm{Hb}-10 \mathrm{gm} \%$, TLC-7800, DLC-P64L32M2E2, Urine RE$\mathrm{NAD}$, Blood group - $\mathrm{O}^{+\mathrm{ve}}$ and $\mathrm{UPT}^{+\mathrm{ve}}$. USG of pelvis and abdomen detected to have a viable intrauterine pregnancy with haemoperitoneum and a right adnexal mass suggestive of either a ruptured corpus luteal cyst or ruptured tubal gestation.

Considering the possibility of heterotopic pregnancy, she was planned for diagnostic laparoscopy under spinal 
anaesthesia to have minimal effect on intrauterine viable early pregnancy. On laparoscopy there was marked haemoperitoneum with right tubal isthmic rupture which was managed by laparoscopic salpingectomy (Figure 1, 2 and 3) and peritoneal toileting. Post op recovery was uneventful, and USG confirmed viable intrauterine pregnancy on second post-operative day.

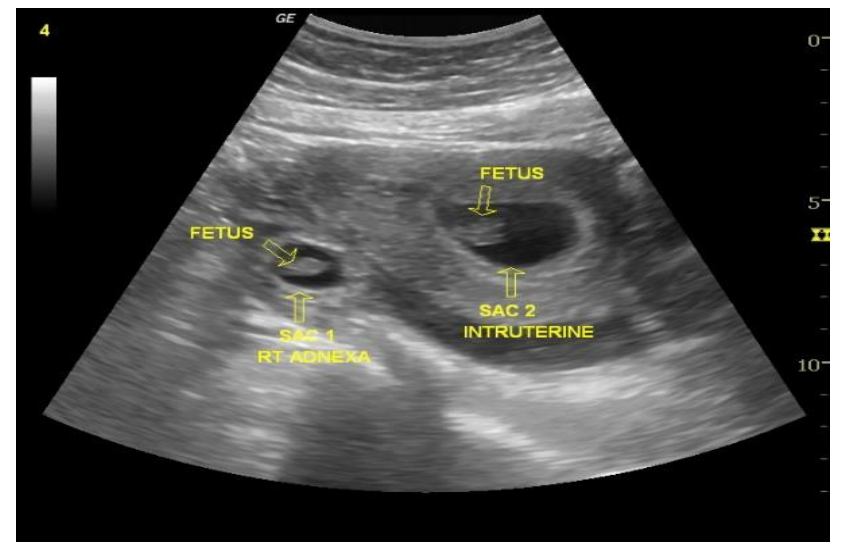

Figure 1: USG finding and laparoscopic salpingectomy of heterotypic pregnancy.

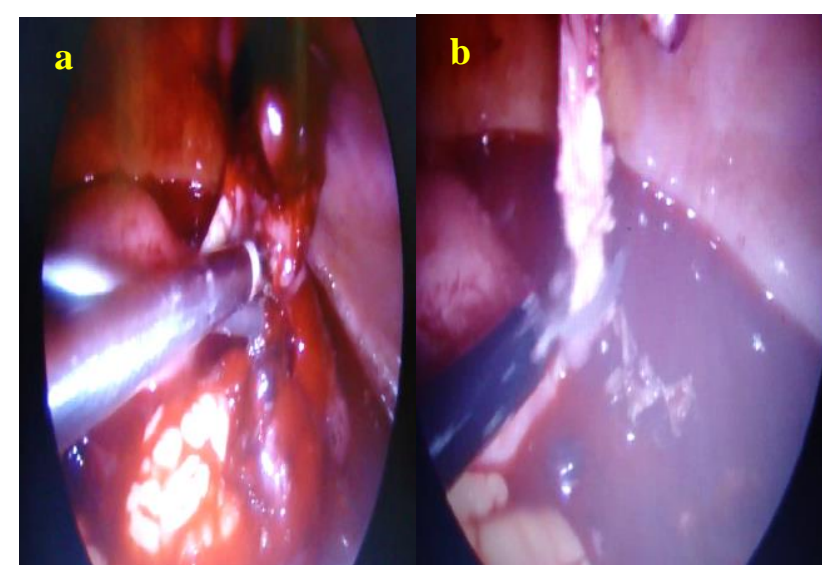

Figure 2: a) and b) Haemoperitoneum with right tubal ruptured ectopic being managed laparoscopically.

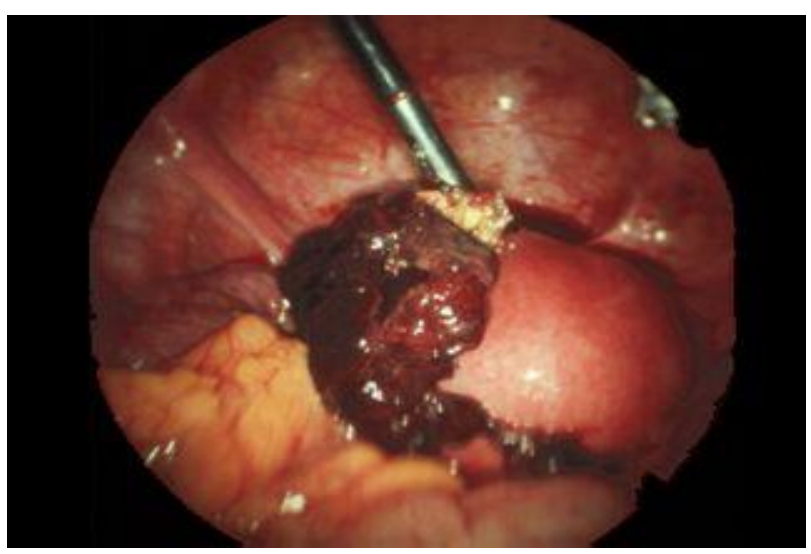

Figure 3: Haemoperitoneum at the end of salpingectomy.
HPE report of the specimen confirmed ruptured tubal ectopic pregnancy. Patient was subsequently discharged with progesterone supports and haematinics. The entire antenatal period of the pregnancy remained uneventful with satisfactory maternal health and foetal growth. At 37 weeks POG, she underwent emergency LSCS for intrapartum foetal distress during labour induction for PROM and delivered a healthy female baby of $2.8 \mathrm{Kg}$ and had an uneventful post op recovery. The object of this case report is to highlight the rarity of the diagnosis, discuss the importance of early diagnosis and bring out the dilemma in the diagnosis and management of spontaneous heterotopic pregnancies.

\section{DISCUSSION}

Early diagnosis of heterotopic pregnancy is difficult because of rarity of this entity especially in non-ART scenario and hence even clinical symptoms are overlooked. Classically, an ectopic pregnancy can present with amenorrhea, pain abdomen and bleeding as early symptoms and abdominal pain due to peritoneal irritation and adnexal mass with or without bleeding per vaginum and hypovolemic shock if ruptured. However, in presence of an intrauterine pregnancy, these symptoms are attributed to threatened abortion and mostly a heterotopic pregnancy is not considered. The recent advances in beta hCG determination and transvaginal USG have aided in the early diagnosis of heterotopic pregnancy. USG, especially transvaginal scanning, has proven to be a valuable tool in the diagnosis of this condition. At times, even with TVS, the adnexal sac can be mistaken for a hemorrhagic corpus luteal or ovarian cyst, especially in hyperstimulated ovaries. Heterotopic pregnancy often goes unnoticed in the presence of IU pregnancy. The sensitivity of TVS in diagnosing heterotopic pregnancy is only $56 \%$ at 5-6 weeks. Generally, it is not easy to differentiate anembryonic adnexal ectopic pregnancy from hemorrhagic corpus luteal cyst at TVS., ${ }^{2,3}$

The management of heterotopic pregnancy remains controversial. The main issue in the treatment of the HP is to be as minimally invasive as possible to preserve the developing intrauterine pregnancy (IUP). Laparotomy is classically reserved for cases with life threatening haemoperitoneum and hypovolaemic shock. Operative laparoscopy is not absolutely contraindicated. ${ }^{4}$ For interstitial or cornual pregnancies, medical termination of the ectopic pregnancy can be performed by injection of potassium chloride into the gestational sac if the ectopic sac is unruptured and clearly visualized. ${ }^{5}$ This is a minimally invasive procedure and does not jeopardize a viable IUP. Successes have been reported in cornual, interstitial and ampullary heterotopic pregnancy. ${ }^{5-8}$ The safety of laparoscopy during pregnancy has been well documented for cholecystectomy, ovarian cystectomy, and heterotopic pregnancy., ${ }^{5,11}$. The procedure is only slightly modified by the presence of the IUP. Specifically, cannulation or excessive manipulations of the uterus are both avoided. The advantages of 
laparoscope over laparotomy in post-surgical recovery are well known and fertility results are similar to those observed with open surgery. ${ }^{12,13}$

\section{CONCLUSION}

Heterotopic pregnancy is a rare clinical situation. Intrauterine viable pregnancy with acute abdomen and haemoperitonium can raise a suspicion of ruptured heterotopic pregnancy. Clinicians should maintain a high index of suspicion in all patients presenting with amenorrhoea and abdominal pains even if an intrauterine pregnancy has been confirmed and a thorough evaluation of the adnexa using a trans-vaginal ultrasound scan should be routinely performed in such cases. In modern era of clinical practice laparoscope remains the gold standard in both diagnosis as well as management of even heterotopic pregnancy where chances of disturbance to the ongoing intrauterine pregnancy is minimum.

Funding: No funding sources

Conflict of interest: None declared

Ethical approval: Not required

\section{REFERENCES}

1. Dündar O, Tütüncü L, Müngen E, Muhcu M, Yergök YZ. Heterotopic pregnancy: Tubal ectopic pregnancy and monochorionic monoamniotic twin pregnancy: A case report. Perinatal J. 2006;14(2):96-100.

2. Callen PW. Ultrasonography in obstetrics and gynecology. Levine D; In: Ectopic pregnancy. $5^{\text {th }}$ ed. Philadelphia: Saunders Elsevier; 1020-1047.

3. Farghaly M, Saeed M. Primary Ovarian Pregnancy. Ain Shams J Obstet Gynecol. Available at www.asjog.org.

4. Soriano D, Yefet Y, Oelsner G, Goldenberg M, Mashiach S, Seidman DS. Is operative laparoscopy contraindicated in women with ectopic pregnancy and hypovolemic shock?. J Am Assoc Gynecol Laparosc. 1996;3(4):S47.
5. Fernandez H, Lelaidier C, Doumerc S, Fournet P, Olivennes F, Frydman R. Nonsurgical treatment of heterotopic pregnancy: a report of six cases. Fertility and sterility. Fertil. Steril. 1993;60(3):428-32.

6. Porreco RP, Burke MS, Parker DW. Selective embryocide in the nonsurgical management of combined intrauterine-extrauterine pregnancy. Obstet Gynecol. 1990;75(3):498-501.

7. Rizk B, Tan SL, Morcos S, Riddle A, Brinsden P, Mason BA, Edwards RG. Heterotopic pregnancies after in vitro fertilization and embryo transfer. Am J Obstet Gynecol.1991; 164(1):161-4.

8. Marcus SF, Macnamee M, Brinsden P. Heterotopic pregnancies after in vitro fertilization and embryo transfer. Hum Reprod. 1995;10:1232-36.

9. Hanf V, Dietl J, Gagsteiger F, Pfeiffer KH. Bilateral tubal pregnancy with intra-uterine gestation after IVF-ET: therapy by bilateral laparoscopic salpingectomy; a case report. Eur J Obstet Gynecol Reprod Biol. 1990;37(1):87-90.

10. Soper NJ, Hunter JG, Petrie RH. Laparoscopic cholecystectomy during pregnancy. Surg. Endosc. 1992;6:115-7.

11. Curet MJ, Allen D, Josloff RK, Pitcher DE, Curet LB, Miscall BG, Zucker KA. Laparoscopy during pregnancy. Arch. Surg. 1996;131(5):546-50.

12. Murphy AA. Operative laparoscopy. Fertil Steril. 1987;47:1-18.

13. Lundorff $\mathrm{P}$, Thorburn J, Lindblom B. Fertility outcome after surgical treatment of ectopic pregnancy evaluated in a randomized trial. Fertil. Steril. 1992;57:998-1002.

Cite this article as: Maiti GD, Jose T, Gupta S, Chatterjee V. A rare case of spontaneous heterotopic pregnancy with successful pregnancy outcome following laparoscopic management of coexisting ruptured tubal pregnancy in Non-ART set up. Int J Reprod Contracept Obstet Gynecol 2018;7:2515-7. 